\title{
Ambidexterity and agility in achieving dry port effectiveness in the greater Jakarta
}

\author{
Maria Grace Herlina ${ }^{a}$, Lasmy ${ }^{a}$, Darjat Sudrajat ${ }^{\mathrm{a}}$, Dicky Hida Syahcharia ${ }^{\mathrm{a}}$, Hardijanto Saroso ${ }^{\mathrm{a}}$ and \\ Erik Van Zanten ${ }^{b}$
}

${ }^{a}$ Management Department, BINUS Business School Undergraduate Program, Universitas Bina Nusantara, Jakarta, Indonesia ${ }^{b}$ HAN University of Applied Sciences, Arnhem and Nijmegen, Netherlands

\begin{tabular}{l}
\hline C H R O N I C L E \\
\hline Article history: \\
Received November 8, 2020 \\
Received in revised format \\
January, 28, 2021 \\
Accepted March 242021 \\
Available online \\
March 25 2021 \\
\hline Keywords: \\
Ambidexterity \\
Agility \\
Organizational effectiveness \\
ICT \\
Social web
\end{tabular}

\section{A B S T R A C T}

\begin{abstract}
Dry Port, a supply chain company, strives to bring its workers up to speed in the current VUCA world. The study explores the degree to which ambidexterity affects agility, which can impact organizational effectiveness. The structural equation model with multilevel simulation used to test the research hypothesis. The study indicates that ambidexterity is an influential factor to agility, and that ambidexterity is also an impactful factor to agility and organizational effectiveness. Furthermore, there is also evidence that the power of agility contributes to greater organizational effectiveness, and also that ambidexterity has an impact on organizational effectiveness through workforce agility. To achieve organizational effectiveness in dry port business, mobile devices and social network technology are functional enablers of ambidextrous activities that can allow staff to be agile in handling dry port business tasks.
\end{abstract}

(C) 2021 by the authors; license Growing Science, Canada.

\section{Introduction}

The current market climate has become competitive, complex, and uncertain (VUCA), with dynamic opportunities and challenges that arise, evolve, or disappear (Munteanu, Bibu, Nastase, Cristache, \& Matis, 2020). The modern market climate has changed how an organization works and how it competitively delivers products and services. The innovation push, expertise, and skills of employees reflect the strengths of a company that seeks to implement more sustainable development and business strategy, enabled by high technology and digitalization (Muduli, 2016, 2017; Munteanu et al., 2020). The supply chain is the activity that promotes cooperation between stakeholders and business aspects such as inventory, rapid response, minimizing operating costs, and increasing profitability (Saa'da, Suifan, \& Al-Saa'da, 2020). Successful human resource management is crucial in a company's competitive advantage in the supply chain industry (Anastasiou, 2016). Dry Port is a major inland port as it services inland intermodal facilities. These gateways have close links to seaports for regular shipping. The high volume and regular transport services support the dry port's good connectivity and cooperation. From the supply chain point of view, dry ports might act as extensions of nearby seaports or inland shipping hubs to facilitate cargo movement between port and hinterland. Integrated transportation through dry ports is cost-efficient and fast transport (Jeevan \& Roso, 2019; Nguyen \& Notteboom, 2016). The supply chain industry's management must contend with physical constraints such as the physical boundaries that constrain the chain. Data, communication, and mobile technologies are used to overcome conventional spatial and temporal boundaries and realize quick action and organizational flexibility. The integration of technological innovations and developments in the workplace has revolutionized conventional workplace practices (Breu, Hemingway, Strathern, \& Bridger, 2002). This study proposes that electronic forms of communication and virtual organization of employees are required to help supply chain business processes in dry ports. The ICT infrastructure for dry ports is at the core of a company that uses telecommunications extensively. When done well, the ICT infrastructure

\footnotetext{
* Corresponding author

E-mail address: herlina01@binus.edu (M. G. Herlina)

C 2021 by the authors; licensee Growing Science. doi: $10.5267 /$ j.uscm.2021.3.008
} 
helps the company construct adaptive and sensitive buildings that can adapt to the dynamic climate. A crucial component of the infrastructure is the technology that enhances immediate access to organizational information and knowledge services while also enhancing information management's timeliness (Breu et al., 2002; Saa'da et al., 2020).

Organizational performance is measured on the achievement of particular targets within a given period. The company's primary resources are human resources; therefore, the company's results are decided by its employees. The employee performance metrics are the job's consistency, quantity, effectiveness, and behaviors that impact interpersonal relationships (Hermawati, Suci, \& Karyanto, 2020; Sutia, Riadi, \& Fahlevi, 2020). Employee ambidexterity happens when workers display a mixture of exploratory behaviors and exploitative behaviors (Alghamdi, 2018). Exploring involves looking for alternatives, finding, generating and playing with new possibilities, accomplishing assignments, and learning from errors, while exploiting is choosing, introducing, enhancing and refining established certainties. In short, explorative is about trying out something new, while exploitative relies on one's experience, designing a strategy, and implementing the plan (Peng, Lin, Peng, \& Chen, 2019; Rosing \& Zacher, 2017). Accumulated organizational expertise promotes adaptability. Using employees' expertise and experience will promote agility. An organization that wishes to respond to marketplace demands rapidly should concentrate on technology and train employees in technology use. A company's learning environment can help people become more creative in their thoughts and make discoveries. It also encourages the acquisition of expertise in enhancing strategic versatility to adapt to the changes that will lead to organizational effectiveness (Muduli, 2016, 2017). Organizational effectiveness is defined as the firm's capacity to recognize and maximize opportunities in the environment through capital allocation. The organizational effectiveness approaches examine organizational processes, organizational resources, and the function of interactions between organizational factors that will lead to profitability, creativity and efficiency (Kareem \& Hussein, 2013). This research aims to look into workforce ambidexterity and agility of exploring and leveraging information through ICT, in achieving organizational effectiveness of dry ports business.

\section{Literature Review}

\subsection{Ambidexterity}

Ambidexterity is a situation where the activities of discovery and exploitation are at odds with one another (Alghamdi, 2018; Rosing \& Zacher, 2017; Zhang, Wei, \& Van Horne, 2019). Other similar characteristics are alignment and adaptability, agility and stability, teamwork and individual focus (Zhang et al., 2019). Some scholars explain that such items can be in both the organizational sense and the team context. Exploration focuses on search, discovery, and risk-taking, and exploitation concerns execution, performance, refinement, selection, implementation and risk avoidance (Alghamdi, 2018; Rosing \& Zacher, 2017). Organizational ambidexterity is a recent concept in organizational dynamics. It involves the production of new goods and services (Alghamdi, 2018; Peng et al., 2019; Schnellbächer \& Heidenreich, 2020). Ambidexterity is a trait of an organization's ability to react to rapid change. It works concurrently with existing capabilities to leverage opportunities and investigates potential possibilities (Alghamdi, 2018; Schnellbächer \& Heidenreich, 2020). At the individual level, ambidexterity means that both exploration and exploitation will occur to achieve synergisms. Empirical research has shown that ambidexterity positively affects organizational agility and organizational effectiveness. Based on the scholar's explanation, ambidexterity defines as a way to leverage information generation and accumulation from exploration and exploitation processes to optimize organizational effectiveness and efficiency (Mu, van Riel, \& Schouteten, 2020; Papachroni \& Heracleous, 2020; Schnellbächer \& Heidenreich, 2020; Tuan Trong, Rowley, \& Khai, 2018; Zhang et al., 2019).

\subsection{Agility}

The impact of ambidexterity is agility. At the individual level, agility is similar to workforce resilience, which means the capacity to take swift and effective action when required changes occur (Alghamdi, 2018; Zhang et al., 2019). Therefore, an agile workforce encourages agile culture and constructive agility in the workplace. Organizational agility can be accomplished by teamwork, allegiance and workers' ability and experience, and workers' attitude and actions. These are adaptability, cooperation, growth, energetic, versatility, efficient, speedy and competent (Al-Kasasbeh, Halim, \& Omar, 2016; Muduli, 2016, 2017).

There are three dimensions of the agile workforce. The first is proactiveness. It predicts challenges associated with transition and addresses them by implementing tasks and job changes. Second, adaptability. It is the ability to take on multiple roles, move rapidly from one role to another, and work concurrently on various crucial tasks. The last is resilient behaviour that requires a positive attitude about transitions, new ideas, technology, and tolerance to unpredictable and unforeseen circumstances and dealing with stress (Muduli, 2016, 2017). Agile workers are inclined toward learning, self-development, successful problem-solvers, comfortable with change and new thinking, technology, and ideas ever ready for the next challenge (Muduli, 2016, 2017). Empirical research has shown that agility has a beneficial impact on organizational effectiveness (AL-Kasasbeh et al., 2016; Aladwan, 2017; Jalal, Jehangir, \& Ullah, 2017; Muduli, 2016, 2017; Zhang et al., 2019). Based on the scholars' viewpoints, agility is described as the employee's capacity to adjust to changing circumstances 
and change direction accordingly. It enables them to transform a transition into an opportunity for growth (Breu et al., 2002; Muduli, 2016, 2017; Zhang et al., 2019).

\subsection{Organizational Effectiveness}

Performance-oriented principles, such as Organizational Effectiveness (OE), are essential for management. The focus of the study is on performance, competitiveness, excellence, and total quality. Human Resources Management (HRM) contributes to the overall organizational effectiveness, such as organizational capacity, intellectual resources, highperformance work processes, and high-performing teams. Organizational effectiveness describes the degree to which an organization can accomplish the goals it has set out to achieve. The beneficial influence of ambidexterity and organizational agility has been demonstrated by comprehensive empirical study; therefore, the research hypotheses are:

Hypothesis 1: Employee ambidexterity has a positive impact on employee agility significantly.

Hypothesis 2: Employee ambidexterity has a positive impact on organizational effectiveness significantly.

Hypothesis 3: Employee agility has a positive impact on organizational effectiveness significantly.

Hypothesis 4: Employee ambidexterity has a positive impact on organizational effectiveness through employee agility significantly.

\section{Research Methodology}

The study aims to explore the impact of ambidexterity, assisted by information and communications technology (ICT), on the workforce's agility and organizational effectiveness in Dry Port (DP) business. The research was performed from October 2020 to December 2020. The quantitative analysis using Structural Equation Modeling (SEM). The number of respondents was 130 . The respondents were $77 \%$ male staff, 33\% female staff, a high school education $13 \%, 29 \%$ diploma graduates, $56 \%$ bachelor degree graduates, and a $2 \%$ master degree. Those are $52 \%$ staff, $23 \%$ supervisor, $17 \%$ manager, and $2 \%$ director with one to five years tenure $59 \%$, six to ten years tenure $37 \%$, and more than ten years tenure is around $4 \%$. The ambidexterity instrument consists of four indicators. Those are explorative knowledge-seeking, exploitative knowledge-seeking, explorative knowledge offering, and exploitative knowledge offering. Simultaneously, the agility instrument consists of five indicators - intelligence, competency, collaboration, resiliency, and culture. The dry port effectiveness consists of five indicators. Those are Job Satisfaction, Profitability, Productivity, Efficiency, and Innovation. Those indicators will be testing to assess the validity and reliability of the research instruments. The team generated questions that related to the meanings of the terms and dimensions of each concept. This study performed a model analysis using two evaluation methods: an outer model (measurement model) and an inner model (structural model). The Outer Model measures the convergent, discriminant and composite reliability of the tests. The Convergent Validity Test used to verify the reliability of an indicator with a latent build. The research results meet the convergent validity test if it has a loading factor above 0.700 and an AVE value greater than 0.5 . The following table shows the research results based on the loading factor and AVE.

Table 1

\begin{tabular}{|c|c|c|c|c|}
\hline Variables & Indicators & Loading Factor & Cut Off & Result \\
\hline \multirow{4}{*}{ Ambidexterity (X)/Abx } & $\mathrm{X}_{1}$ & 0.890 & \multirow{14}{*}{0.7} & \multirow{14}{*}{ Valid } \\
\hline & $X_{2}$ & 0.885 & & \\
\hline & $\mathrm{X}_{3}$ & 0.744 & & \\
\hline & $\mathrm{X}_{4}$ & 0.760 & & \\
\hline \multirow{5}{*}{ Agility (Y)/Ag } & $\mathrm{Y}_{1}$ & 0.874 & & \\
\hline & $\mathrm{Y}_{2}$ & 0.880 & & \\
\hline & $\mathrm{Y}_{3}$ & 0.758 & & \\
\hline & $\mathrm{Y}_{4}$ & 0.833 & & \\
\hline & $\mathrm{Y}_{5}$ & 0.823 & & \\
\hline \multirow{5}{*}{ Organizational Effectiveness (Z)/OE } & $\mathrm{Z}_{1}$ & 0.752 & & \\
\hline & $\mathrm{Z}_{2}$ & 0.791 & & \\
\hline & $\mathrm{Z}_{3}$ & 0.836 & & \\
\hline & $\mathrm{Z}_{4}$ & 0.890 & & \\
\hline & $Z_{5}$ & 0.909 & & \\
\hline
\end{tabular}

The data shows all of the indicators have a higher factor loading value than 0.7 , which means those are valid. It means that all indicators can explain each existing variable, and those are also meaningful enough for further study. The results show that all variables have an Average Variance Extracted (AVE) value of more than 0.5. Thus, all indicators can be declared capable of measuring the variables. The following research instrument analysis is Discriminant Validity Test. It determines whether the construct has sufficient discriminant. The criterion is the loading value of the intended construct must be greater than the loading value of other constructs. Thus, these indicators showed validity in measuring the corresponding variables. 
Table 2

Validity Construct Test Result using AVE

\begin{tabular}{cccc}
\hline Variable & Average Variance Extracted (AVE) & Sig. & Result \\
\hline $\mathbf{X}$ & 0.677 & 0.5 & 0.5 \\
$\mathbf{Y}$ & 0.697 & 0.5 \\
\hline $\mathbf{Z}$ & 0.702 & Valid \\
\hline
\end{tabular}

Table 3

Fornel-Locker

\begin{tabular}{cccc}
\hline Variables & $\mathbf{X}$ & $\mathbf{Y}$ & \\
\hline $\mathbf{X}$ & $\mathbf{0 . 8 2 3}$ & $\mathbf{0 . 8 3 5}$ & \\
$\mathbf{Y}$ & 0.612 & 0.635 & $\mathbf{0 . 8 3 8}$ \\
\hline $\mathbf{Z}$ & 0.646 & 0.635 \\
\hline
\end{tabular}

*) the values listed in the diagonal direction are the AVE root values

The Fornel-Locker result (Table 3 ) shows that the AVE root value for the ambidexterity variable is 0.823 . The ambidexterity variable's highest correlation value is 0.646 , which is the correlation between ambidexterity and OE. Simultaneously, the AVE root value for the agility variable is 0.835 , while the highest correlation value for the agility variable is 0.635 , which is the correlation between agility and OE. Furthermore, the AVE's root value for the OE variable is 0.838 , while the highest correlation value for the $\mathrm{OE}$ variable is 0.646 , which is the correlation between $\mathrm{OE}$ and ambidexterity.

Table 4

Validity Construct Test Result using Cross Loading

\begin{tabular}{|c|c|c|c|}
\hline Indicators & $\mathbf{X}$ & $\mathbf{Y}$ & $\mathbf{Z}$ \\
\hline $\mathbf{X}_{1}$ & 0.890 & 0.520 & 0.637 \\
\hline $\mathbf{X}_{2}$ & 0.885 & 0.569 & 0.586 \\
\hline $\mathbf{X}_{3}$ & 0.744 & 0.520 & 0.491 \\
\hline $\mathbf{X}_{4}$ & 0.760 & 0.370 & 0.356 \\
\hline$Y_{1}$ & 0.570 & 0.874 & 0.587 \\
\hline $\mathbf{Y}_{2}$ & 0.518 & 0.880 & 0.508 \\
\hline $\mathbf{Y}_{3}$ & 0.462 & 0.758 & 0.493 \\
\hline $\mathbf{Y}_{4}$ & 0.473 & 0.833 & 0.507 \\
\hline$Y_{5}$ & 0.520 & 0.823 & 0.548 \\
\hline $\mathbf{Z}_{1}$ & 0.593 & 0.560 & 0.752 \\
\hline $\mathbf{Z}_{2}$ & 0.545 & 0.436 & 0.791 \\
\hline $\mathbf{Z}_{3}$ & 0.484 & 0.506 & 0.836 \\
\hline $\mathbf{Z}_{4}$ & 0.578 & 0.564 & 0.890 \\
\hline $\mathbf{Z}_{5}$ & 0.487 & 0.575 & 0.909 \\
\hline
\end{tabular}

Based on the analysis result in table 4 , in the ambidexterity variable, $\mathrm{X}_{1}-\mathrm{X}_{4}$ indicators have a higher cross-loading value for the variable than the cross-loading value for other variables. It infers that the ambidexterity variable meets the requirements for discriminant validity. The Y1-Y5 indicator has greater cross loading value for the variable than the cross loading value for other variables in the agility variable. It means the agility variable meets the requirements for discriminant validity. The $O E$ variable explains that the $Z_{1}-Z_{5}$ has a greater cross-loading value for the variable than the cross-loading value for other variables meaning the $\mathrm{OE}$ variable meets the discriminant validity requirements. The reliability test was using Cronbach's alpha and Composite Reliability to strengthen the research instrument. The test criteria stated that if composite reliability is more significant than 0.7 and Cronbach's alpha is greater than 0.6 , then the construct is reliable.

Tabel 5

Reliability Test Results

\begin{tabular}{cccc}
\hline & Cronbach's Alpha & Composite Reliability & Result \\
\hline X & 0.840 & 0.893 & Reliable \\
Y & 0.890 & 0.920 & \\
\hline
\end{tabular}

The reliability test results indicate that each variable exhibits sufficient reliability since each variable produces a Cronbach's alpha value greater than 0.6 . Besides, the composite reliability is more than 0.7 . It concludes that all of the variables that were measured are reliable.

\section{Analysis and Discussion}

Inner Model Evaluation used to evaluate the goodness of fit, including $\mathrm{R}^{2}, \mathrm{f}^{2}, \mathrm{Q}^{2}$, and hypothesis testing. The structural research model present in figure 1 . The model shows that the value of $\mathrm{R}^{2}$ agility is 0.374 , meaning that the ambidexterity variable influences agility by $37.4 \%$. In comparison, the rest is influenced by other factors that were not examined $(0.626$ 
or $62.6 \%$ ). The ambidexterity path coefficient is 0.612 in a positive direction, meaning that there is a unidirectional relationship. If ambidexterity increases by 1 unit, then agility will increase by 0.612 . The value of $\mathrm{R}^{2}$ of $\mathrm{OE}$ is 0.510 , meaning that $\mathrm{OE}$ is influenced by ambidexterity and agility by $51.0 \%$. In comparison, the rest is influenced by other factors that were not examined $(0.490$ or $49.0 \%)$.

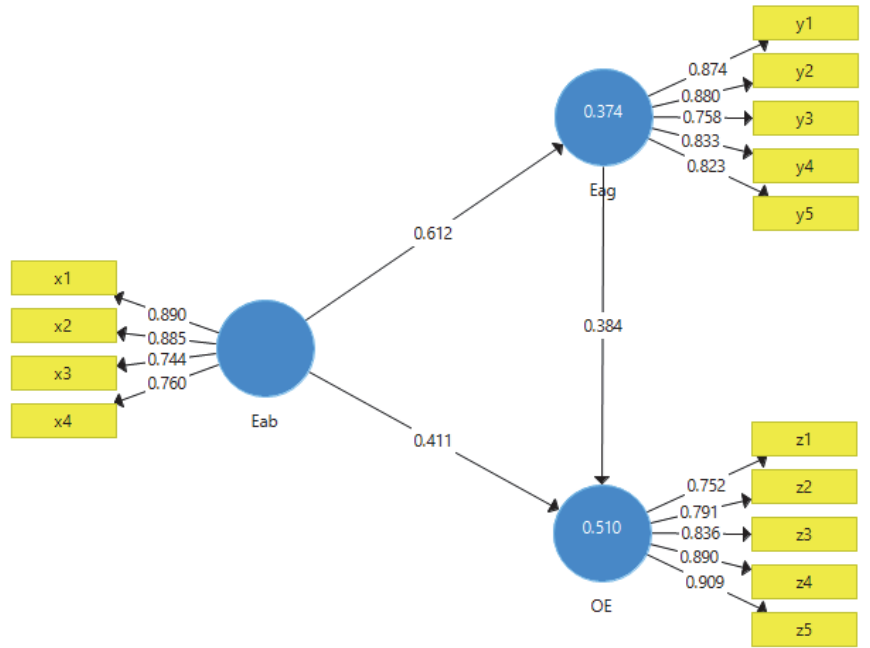

Fig. 1. Standardized Research Model

The ambidexterity path coefficient is 0.411 in a positive direction, meaning that there is a unidirectional relationship. If ambidexterity increases by 1 unit, organizational effectiveness will increase by 0.411 . The agility path coefficient is 0.384 in a positive direction, meaning that there is a unidirectional relationship. If agility increases by 1 unit, organizational effectiveness will increase by 0.384. The next analysis is testing Bootstrapping Hypotheses (Path Analysis). Hypothesis testing is used to test the influence of exogenous variables on endogenous variables. The test criteria state that if the $\mathrm{T}$ statistics value $\geq \mathrm{T}$-table (1.96) or the $\rho$ value $<$ significant alpha $5 \%$ or 0.05 , it is stated that there is a significant effect of exogenous variables on endogenous variables. The results of the significance and model testing can be seen through the following figures and tables.

Table 6

Path Coefficient

\begin{tabular}{cccc}
\hline & Original Sample (O) & T Statistics $(\mid \mathbf{O} /$ STDEV $\mid)$ & $\rho$ value \\
\hline $\mathrm{Abx} \geq \mathrm{Ag}$ & 0.612 & 5.804 & 0.000 \\
$\mathrm{Abx} \geq \mathrm{OE}$ & 0.411 & 2.880 & 0.006 \\
$\mathrm{Ag} \geq \mathrm{OE}$ & 0.384 & 2.779 & 0.008 \\
\hline
\end{tabular}

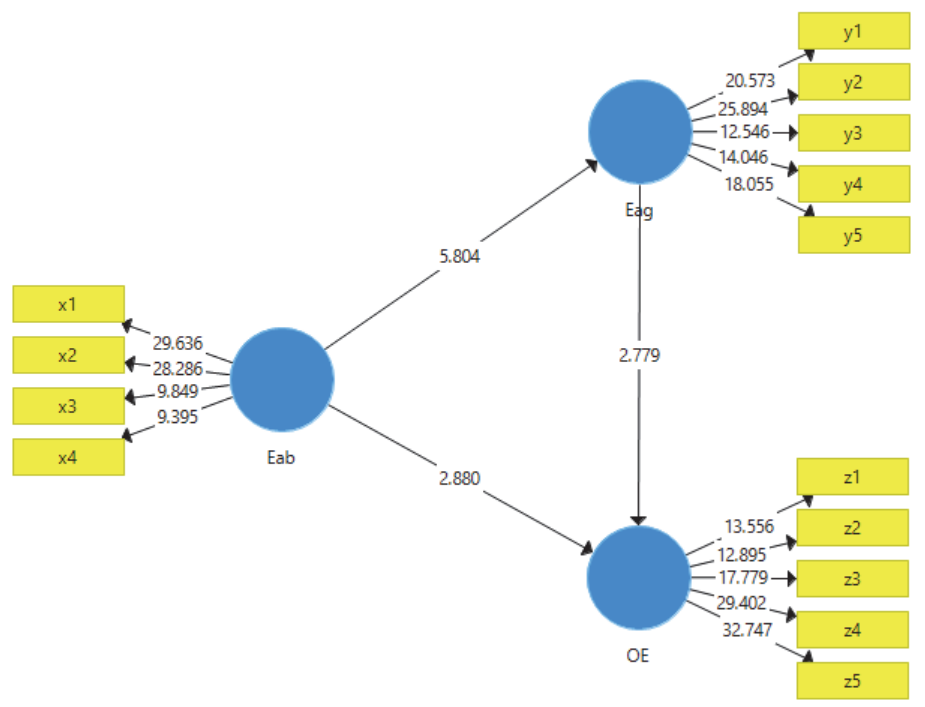

Fig. 2. Inner Model Analysis 
Hypothesis 1 is the significant influence of ambidexterity on agility. The test result shows the path coefficient value is 0.612 with T statistics of 5.804 with a $\rho$ value of 0.000 . The test results show that the value of T statistics $>1.96 \rho$ value $<0.05$. It means that there is a significant influence of ambidexterity on agility so that $\mathrm{H}_{1}$ is accepted.

Hypothesis 2 is the significant influence of ambidexterity on OE. The test result shows that the path coefficient value is 0.411 with a $T$ statistics of 2.880 with a $\rho$ value of 0.006 . The test results show that the value of T statistics $>1.96$ and $\rho$ value $<0.05$. It means that there is a significant influence of ambidexterity on $\mathrm{OE}$ so that $\mathrm{H}_{2}$ is accepted.

Hypothesis 3 is the significant influence of agility on OE. The test results show that the path coefficient value is 0.384 with a T statistics of 2.779 with a $\rho$ value of 0.008 . The test results show that the value of T statistics $>1.96$ and $\rho$ value $<0.05$. It means that there is a significant influence of agility on $\mathrm{OE}$ so that $\mathrm{H}_{3}$ is accepted.

Hypothesis 4 is the significant influence of ambidexterity on OE through agility. The researcher used the indirect effect output to examine $\mathrm{H}_{4}$.

Tabel 7

Specific Indirect Effect Value

\begin{tabular}{cccc}
\hline Variables & Original Sample (O) & T Statistics (|O/STDEV $\mid)$ & $\rho$ value \\
\hline $\mathrm{Abx} \geq \mathrm{Ag} \geq \mathrm{OE}$ & 0.235 & 2.094 & 0.042 \\
\hline
\end{tabular}

The test results explain that the path coefficient value is 0.235 with a T statistics of 2.094 with a $\rho$ value of 0.042 . The test results show that the value of $\mathrm{T}$ statistics $>1.96$ and $\rho$ value $<0.05$. It means that there is a significant influence of ambidexterity on organizational effectiveness through agility so that $\mathrm{H}_{4}$ is accepted. These hypotheses testing results can support the empirical research of previous scholars (AL-Kasasbeh et al., 2016; Aladwan, 2017; Jalal et al., 2017; Mu et al., 2020; Muduli, 2016, 2017; Papachroni \& Heracleous, 2020; Tuan Trong et al., 2018; Zhang et al., 2019). The study showed that being ambidextrous improved the personnel, team, and organization's creative and critical thinking abilities. Ambidexterity is similar to knowledge-based practices that exhibit exploratory and exploitative knowledge seeking. It is an integrated knowledge-based synergy involving ambidexterity. Information obtained from the combination of feedback from exploration and exploitation processes would be conducive to successful knowledge accumulation. It provides them with a bridge between their shifting world and prospects for advancement. Conducting knowledge-based activities will support collaboration, creativity, and connectivity to achieve employee agility. As a supply chain business, Dry port requires the ICT infrastructure to provide real-time and remote access to information and knowledge services to increase action pace. Mobile communications can assist in port-related business processes by providing a digital forum for port staff to communicate. They improve communication speed regardless of distance and location due to the high connectivity of modern communication networks(Breu et al., 2002). They also allow the exchange of rich information necessary for a successful virtual organization using mobile technologies such as voice mail, email, fax, or the internet that can support workforce collaboration even when they are physically far apart. Dry ports need mobile technologies that are highly dynamic, flexible, and agile with high operational flexibility to more effectively facilitate supply chain services. Mobile technologies need to help the "dry port" effectiveness and to be able to overcome time and space barriers, including realtime communication.

The primary enabler of ambidextrous activity is the availability of information and communication technologies (ICT). The dry port social network will help both tacit and real-time knowledge exchange. It may also provide opportunities to gather an individual's experiences and information to create new knowledge as a knowledge-seeking product (Panahi, Watson, \& Partridge, 2012, 2013). Dry Port social network resources, such as podcasts/vodcasts, provide a transfer of multimedia, such as images and audio-video, to allow for knowledge offerings. The resources illustrate technological know-how and transition experiences and offer an overview of the dry port industry. Social-based media promotes and embraces flexible and diverse management outcomes (Chow, 2011; Panahi et al., 2012, 2013). Social Networking Sites (SNS) prove to be another way to promote ambidextrous functioning. It will allow the exploration and exploitation of the dry port knowledge by keeping the dry port process going. It is also a foundation for tacit knowledge exchange in the social community of practices $(\mathrm{CoP})$, an essential component to individual growth. It will also help to develop peer-to-peer relationships and establish a personal, professional exchange of experiences and expertise. It would be beneficial to embed instant messaging and discussion forums to enable concurrent and shared real-time data in SNS environments. It will promote the organizational ambidexterity and keeping the staff agile, which has benefits such as dry port effectiveness (BecerraFernandez, 2009; Chow, 2011; Panahi et al., 2013) (Becerra-Fernandez, 2009; Owen, 2006; Panahi et al., 2013).

\section{Conclusion}

These research findings support the hypothesis that ambidexterity has a significant influence on agility, and ambidexterity significantly influences organizational effectiveness. Agility has a significant impact on organizational effectiveness and also proves the importance of ambidexterity in the production of organizational effectiveness. It is crucial to keep the workforce agile by giving them more opportunities to explore and exploit organizational knowledge to promote innovation 
and sustainable competitive advantage in the supply chain industry, particularly dry port business. ICT can help in ambidextrous activities. Ambidextrous people are innovative in that they put in new information and upgrade existing knowledge. Mobile technologies and social web technology are two of the additional resources rendering ambidextrous activities possible. It is easy to work with and low-cost to use. Mobile technology and the social network allow individual social connections at many different levels. Therefore, it provides daily ambidextrous activities in the dry port industry to preserve the business's effectiveness. The study still needs progress. It would be useful to increase the number of respondents for the study and explore other important factors such as leadership, work culture, and others. It would be helpful if the research instrument re-used for later research, such as exploring ambidexterity as a factor supporting organizational effectiveness with various research contexts. It is also beneficial to study other ICT resources that promote ambidextrous practices and how the evidence for the efficacy supports those tools.

\section{References}

AL-Kasasbeh, A. M., Halim, M. A. S. A., \& Omar, K. (2016). E-HRM, workforce agility and organizational performance: A review paper toward theoretical framework. International Journal of Applied Business and Economic Research, 14(15), 10671-10685.

Aladwan, Z. S. (2017). The Impact of Knowledge Management Processes on Workforce Agility : An Empirical Investigation at Pharmaceutical Companies in Jordan.

Alghamdi, F. (2018). Ambidextrous leadership, ambidextrous employee, and the interaction between ambidextrous leadership and employee innovative performance. Journal of Innovation and Entrepreneurship, 7(1), 1-14. https://oi.org/10.1186/s13731-018-0081-8

Anastasiou, S. (2012, October). Critical human resources management functions for efficient logistics and supply chain management. In Proceedings of the 2nd International Conference on Supply Chains, Katerini, Greece.

Becerra-Fernandez, I. (2009). Knowledge management: an evolutionary view. In M.E.Sharpe, Inc. (Vol. 46). https://doi.org/10.5860/choice.46-2713

Breu, K., Hemingway, C. J., Strathern, M., \& Bridger, D. (2002). Workforce agility: The new employee strategy for the knowledge economy. Journal of Information Technology, 17(1), 21-31. https://doi.org/10.1080/02683960110132070

Chow, N. K. (2011). Factors affecting usage of information technology in support of knowledge sharing: A multiple case study of service organizations in Hong Kong. Journal of Global Information Management, 19(2), 45-66. https://doi.org/10.4018/jgim.2011040103

Hermawati, A., Suci, R., \& Karyanto, B. (2020). Supply Chain Practices of Small and Medium Enterprises as a Maximized Effort of Human Resource Performance Strategy in Tourism Sector. 9(3), 881-891.

Jalal, S., Jehangir, M., \& Ullah, Z. (2017). Organizational Agility Determinants and Performance: A Case of Pakistani Telecommunication Sector. Global Regional Review, 2(1), 211-227. https://doi.org/10.31703/grr.2017(ii-i).15

Jeevan, J., \& Roso, V. (2019). Exploring seaport - dry ports dyadic integration to meet the increase in container vessels size. Journal of Shipping and Trade, 4(1). https://doi.org/10.1186/s41072-019-0047-4

KAREEM, M. A., \& HUSSEIN, I. J. (2013). The Impact of Human Resource Development on Employee Performance and Organizational Effectiveness. Management Dynamics in the Knowledge Economy, 7(3), $307-322$. https://doi.org/10.25019/mdke/7.3.02

Mu, T., van Riel, A., \& Schouteten, R. (2020). Individual ambidexterity in SMEs: Towards a typology aligning the concept, antecedents and outcomes. Journal of Small Business Management, 00(00), 1-32. https://doi.org/10.1080/00472778.2019.1709642

Muduli, A. (2016). Exploring the facilitators and mediators of workforce agility: an empirical study. Management Research Review, 39(12), 1567-1586. https://doi.org/10.1108/MRR-10-2015-0236

Muduli, A. (2017). Workforce agility: Examining the role of organizational practices and psychological empowerment. Global Business and Organizational Excellence, 36(5), 46-56. https://doi.org/10.1002/joe.21800

Munteanu, A. I., Bibu, N., Nastase, M., Cristache, N., \& Matis, C. (2020). Analysis of practices to increase the workforce agility and to develop a sustainable and competitive business. Sustainability (Switzerland), 12(9). https://doi.org/10.3390/SU12093545

Nguyen, L. C., \& Notteboom, T. (2016). A Multi-Criteria Approach to Dry Port Location in Developing Economies with Application to Vietnam. Asian Journal of Shipping and Logistics, 32(1), $23-32$. https://doi.org/10.1016/j.ajsl.2016.03.003

Owen, J. (2006). Integrating Knowledge Management with Programme Management. In International Journal of Knowledge Management (IJKM) (Vol. 2). https://doi.org/10.4018/jkm.2006010104

Panahi, S., Watson, J., \& Partridge, H. (2012). Social media and tacit knowledge sharing: developing a conceptual model. World Academy of Science, ..., 6(4), 1095-1102. Retrieved from http://eprints.qut.edu.au/50068/

Panahi, S., Watson, J., \& Partridge, H. (2013). Towards tacit knowledge sharing over social web tools. Journal of Knowledge Management, 17(3), 379-397. https://doi.org/10.1108/JKM-11-2012-0364

Papachroni, A., \& Heracleous, L. (2020). Ambidexterity as Practice: Individual Ambidexterity Through Paradoxical Practices. Journal of Applied Behavioral Science, 56(2), 143-165. https://doi.org/10.1177/0021886320913048

Peng, M. Y. P., Lin, K. H., Peng, D. L., \& Chen, P. (2019). Linking organizational ambidexterity and performance: The drivers of sustainability in high-tech firms. Sustainability (Switzerland), 11(14). https://doi.org/10.3390/su11143931

Rosing, K., \& Zacher, H. (2017). Individual ambidexterity: the duality of exploration and exploitation and its relationship 
with innovative performance. European Journal of Work and Organizational Psychology, 26(5), 694-709. https://doi.org/10.1080/1359432X.2016.1238358

Saa'da, R. J., Suifan, T. S., \& Al-Saa'da, R. J. (2020). Organizational and managerial barriers in humanitarian organisations in Jordan. International Journal of Supply Chain Management, 9(2), 1-10.

Schnellbächer, B., \& Heidenreich, S. (2020). The role of individual ambidexterity for organizational performance: examining effects of ambidextrous knowledge seeking and offering. Journal of Technology Transfer, 45(5), $1535-1561$. https://doi.org/10.1007/s10961-020-09781-x

Sutia, S., Riadi, R., \& Fahlevi, M. (2020). The influence of supply chain performance and motivation on employee performance. International Journal of Supply Chain Management, 9(2), 86-92.

Tuan Trong, L., Rowley, C., \& Khai, D. C. (2018). Enhancing the effect of frontline public employees' individual ambidexterity on customer value co-creation: Joint effects of ambidextrous leadership and public service motivation. Journal of Business and Industrial Marketing, 33(4), 506-522.

Zhang, Y., Wei, F., \& Van Horne, C. (2019). INDIVIDUAL AMBIDEXTERITY and ANTECEDENTS in A CHANGING CONTEXT. International Journal of Innovation Management, 23(3). https://doi.org/10.1142/S136391961950021X

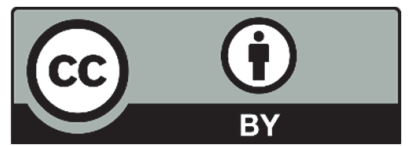

(C) 2021 by the authors; licensee Growing Science, Canada. This is an open access article distributed under the terms and conditions of the Creative Commons Attribution (CC-BY) license (http://creativecommons.org/licenses/by/4.0/). 